\title{
Antinociceptive Action and Redox Properties of Citronellal, an Essential Oil Present in Lemongrass
}

\author{
Lucindo Quintans-Júnior, Ricardo Fagundes da Rocha, ${ }^{2}$ Fernanda Freitas Caregnato, \\ José Claudio Fonseca Moreira, ${ }^{2}$ Francilene Amaral da Silva, Adriano Antunes de Souza Araújo, \\ João Paulo Almeida dos Santos, ${ }^{1}$ Mônica Santos Melo, Damião Pergentino de Sousa, \\ Leonardo Rigoldi Bonjardim, and Daniel Pens Gelain ${ }^{1,2}$ \\ ${ }^{1}$ Department of Physiology, Federal University of Sergipe, Aracaju, Sergipe, Brazil. \\ ${ }^{2}$ Center for Studies in Oxidative Stress, Federal University of Rio Grande do Sul, Porto Alegre, Rio Grande do Sul, Brazil.
}

\begin{abstract}
Citronellal (CT) is a monoterpenoid and the major constituent of the mixture of terpenoids that give the citronella oil its lemon scent. Citronella oil is widely used around the world for various purposes and is mainly obtained from plants of the Cymbopogon genus, which are known as "lemongrass." Considering these plants have been used worldwide for various medicinal purposes, the interest of researchers to understand the biological activities of monoterpenoids related to the Cymbopogon genus has been increasing. In the present work, we investigated the antinociceptive action and the redox properties of CT. Our results indicate that intraperitoneal injection of CT was effective in reducing nociceptive face-rubbing behavior in both phases of the formalin test, which was also naloxone-sensitive. CT also evoked antinociceptive response in the capsaicin and glutamate tests. The total radical-trapping antioxidant parameter and total antioxidant reactivity assays indicate that $\mathrm{CT}$ at doses of 0.1 and $1 \mathrm{mg} / \mathrm{mL}$ exerts a significant antioxidant activity, which is probably related to its ability to scavenge superoxide and nitric oxide, but not $\mathrm{H}_{2} \mathrm{O}_{2}$ or hydroxyl radicals, as evaluated separately by specific in vitro tests. These results show for the first time the antinociceptive potential of CT and indicate that the antioxidant properties of this compound may rely on its mechanism of biological actions because CT-containing natural products are used to treat various diseases related to oxidative stress and reactive species.
\end{abstract}

KEY WORDS: • antinociception $\bullet$ citronellal $\bullet$ free radicals $\bullet$ oxidative stress

\section{INTRODUCTION}

$\mathbf{E}$ PIDEMIOLOGICAL STUDIES have been suggested an inverse correlation between the consumption of certain natural products and the risk of degenerative diseases, cancer, cardiovascular diseases, and chronic pain. ${ }^{1-4}$ The presence of secondary metabolites with antioxidant activity or other redox-related properties is generally associated with such properties, as many of the conditions in which these natural products have been observed to exert a preventive/therapeutic action are strongly related to oxidative stress and increased reactive species production. ${ }^{5,6}$ The increase in reactive species production may result from multiple endogenous (i.e., aging, mitochondrial metabolism) and exogenous (smoke, ultraviolet radiation, pollution) factors and induce oxidative damage to biomolecules such as DNA, proteins, and lipids.

Manuscript received 11 May 2010. Revision accepted 3 August 2010.

Address correspondence to: Daniel Pens Gelain, Ph.D., Departamento de Bioquímica, Universidade Federal do Rio Grande do Sul, Rua Ramiro Barcelos, 2600, anexo, CEP 90035-003, Porto Alegre, RS, Brazil,E-mail: dgelain@yahoo.com.br
The essential oils are natural products that exhibit various biological properties, such as analgesic, ${ }^{7}$ anticonvulsant, ${ }^{8}$ and anxiolytic ${ }^{9}$ effects. Those effects are attributed to the monoterpenes, which are the major chemical components of these essential oils. Citronellal (CT) is a monoterpene product from plant secondary metabolism. It is typically isolated as a non-racemic mixture of its $R$ and $S$ enantiomers by steam distillation or solvent extraction from the oils of Corymbia citriodora Hill and Johnson (former Eucalyptus citriodora Hook), Cymbopogon nardus, Cymbopogon citratus, and Cymbopogon winterianus ("Java citronella"). ${ }^{8,10}$ It is also found in more than 50 other essential oils. Plants from the Cymbopogon genus are known under various names, the most popular being "lemongrass" and "citronella." ${ }^{11}$ Cymbopogon leaves are used as infusion preparations for use as spices, medicinal and recreational teas, soups, and curries. ${ }^{11}$ Other CT-containing plants, such as members of the genuses Eucalyptus, Melissa, Mentha, Allium, and Cinnamomum, among others, also present notable nutritional value and are important food/spice sources in different parts of the world. ${ }^{12}$ In Cymbopogon (lemongrass) and Melissa officinalis (balm), CT is considered a major 
constituent of the leaves, contributing to a great extent of the aromatic scent of these plants. The use of lemongrass in curries in Asia and in spices in Africa is also related to prevention of food spoilage, and the preservative properties of these plants are probably related to their high content of essential oils. ${ }^{13-16}$ Nonetheless, isolated properties of the different essential oil components of these medicinal plants, such as CT, have been poorly studied.

CT is produced by many plants traditionally used to treat different conditions by widespread populations around the world, such as South America and Asia. ${ }^{17-19}$ Although CT has been identified, purified, and chemically well defined, its biological and antioxidant properties have been very poorly explored. For instance, plants of the Cymbopogon genus, which are rich in mono-, di-, and triterpenes, are widely used to treat different forms of pain. ${ }^{20-24}$ Holanda Pinto et al..$^{25}$ demonstrated the analgesic effect of the triterpenoid $\alpha, \beta$ amyrin, a compound closely related to CT. Also, CT and related monoterpenoids were reported to inhibit cytochrome P-450 CYP2B1 and other dehydrogenases, ${ }^{26}$ indicating that such compounds may exert a diverse array of biological actions.

Pain is a complex, multidimensional experience especially relevant to the orofacial region because the face and mouth have a particular biological and psychological meaning for each individual. Many of the most common types of pain occur in the orofacial region, and most difficulties in the management of conditions related to acute and chronic orofacial pain arise from a lack of understanding of its mechanisms. ${ }^{27}$ Free radicals, especially nitric oxide (NO), are also involved in the control of processes related to pain because such species evoke cell signaling cascades related to modulation of neuropathic and inflammatory pain. $^{28}$ In the present work, we investigated the antinociceptive effect of $\mathrm{CT}$ and its redox properties.

\section{MATERIALS AND METHODS}

\section{Animals}

Male Swiss mice (weighing 30-36g) and male Wistar rats (weighing 230-260 g), 2-3 months of age, were used throughout this study. The animals were randomly housed in appropriate cages at $22 \pm 2^{\circ} \mathrm{C}$ on a 12-hour light/dark cycle (lights on 6:00 a.m. to 6:00 p.m.) with free access to food and water. All experiments were carried out between 9:00 a.m. and 2:00 p.m. in a quiet room. Experimental protocols were approved by the Animal Care and Use Committee (CEPA/UFS number 12/08) at the Federal University of Sergipe, Aracaju, Brazil.

\section{Chemicals}

2,2'-Azobis(2-methylpropionamidine) dihydrochloride (AAPH), luminol (5-amino-2,3-dihydro-1,4-phthalazinedione), 2-deoxyribose, glycine (aminoacetic acid), Griess reagent, sodium nitroprusside (SNP), ascorbic acid, 2thiobarbituric acid (TBA) (4,6-dihydroxypyrimidine-2- thiol), hydrogen peroxide, adrenaline, catalase, and superoxide dismutase (SOD) were purchased from Sigma Chemical Co. (St. Louis, MO, USA). Trolox (6-hydroxy2,5,7,8-tetramethylchroman-2-carboxylic acid) was purchased from Aldrich Chemical Co. (Milwaukee, WI, USA). Water was purified using a Milli- ${ }^{\circledR}{ }^{\circledR}$ system from Millipore (Milford, MA, USA). All other reagents used in this study were of highest analytical or high-performance liquid chromatography grade. For all in vivo experiments the following agents were used: CT $[(R S)-( \pm)-\mathrm{CT}, 98 \%$ purity, Dierberger, Barra Bonito, Brazil], morphine hydrochloride (União Química, São Paulo, Brazil), naloxone hydrochloride (Neoquímica, Anapolis, Brazil), 37\% formaldehyde (Vetec, Rio de Janeiro, Brazil), Tween 80 (polyoxyethylenesorbitan monolate), and capsaicin (Sigma). Vehicle for animals was 1 drop of Tween $80(0.2 \%)$ dissolved in $0.9 \%$ $\mathrm{NaCl}$ solution. In those protocols the agents were injected intraperitoneally at a dose volume of $1 \mathrm{~mL} / 10 \mathrm{~g}$. The physiologic solution used for in vivo tests was composed of $150 \mathrm{~m} M \mathrm{NaCl}, 4 \mathrm{~m} M \mathrm{KCl}, 2 \mathrm{~m} M \mathrm{CaCl}_{2}, 1 \mathrm{~m} M \mathrm{MgCl}_{2}$, $10 \mathrm{~m} M$ glucose, and $10 \mathrm{~m} M$ HEPES, adjusted to $\mathrm{pH} 7.4$ with $\mathrm{NaOH}$.

\section{Formalin test}

Orofacial nociception was induced in mice by subcutaneous injection of $20 \mu \mathrm{L}$ of $2 \%$ formalin into the right upper lip (perinasal area), using a 27 -gauge needle. ${ }^{27,29}$ This volume and percentage concentration of formalin were selected from our pilot studies that showed a pain-related biphasic behavioral response (face-rubbing) of great intensity at periods of 0-5 minutes (first phase) and 15-40 minutes (second phase). Pain was quantified at those periods by measuring the time (in seconds) that the animals spent facerubbing in the injected area with their fore- or hindpaws. ${ }^{27}$ To assess the effects of test drugs, groups of rats $(n=8$ per group) were pretreated systemically with vehicle (1 drop of Tween $80[0.2 \%]$ in distilled water, the solvent for CT) or CT (50, 100, and $200 \mathrm{mg} / \mathrm{kg}$, i.p.), 0.5 hours before the local injection of formalin. Morphine ( $3 \mathrm{mg} / \mathrm{kg}$, i.p.), administered 30 minutes before the algogen, was included as the positive control. In separate experiments, the possible involvement of opioid mechanism was assessed in the antinociception produced by CT or morphine with naloxone ( $1.5 \mathrm{mg} / \mathrm{kg}$, i.p.), an opioid antagonist, injected simultaneously.

\section{Capsaicin test}

The orofacial pain was induced by capsaicin administration. Mice $(n=8)$ were injected with capsaicin $(20 \mu \mathrm{L}$, $2.5 \mu \mathrm{g}$ ) subcutaneously into the right upper lip (perinasal area), using a 27-gauge needle. Capsaicin was dissolved in ethanol, dimethyl sulfoxide, and distilled water $(1: 1: 8$ by volume). In pilot studies, rodents manifested pain-related face-rubbing behavior following the injection of capsaicin with a high intensity for a 10-20-minute period. Therefore, pain quantification was performed at this period measuring the time (in seconds) that the animals spent face-rubbing the injected area with their fore- or hindpaws. CT $(50,100$, and 
$200 \mathrm{mg} / \mathrm{kg}$, i.p.) or vehicle ( 1 drop of Tween 80 [0.2\%] in distilled water, the solvent for CT) was given to animals as described for the formalin test, 2 hours before the local injection of capsaicin. Morphine $(5 \mathrm{mg} / \mathrm{kg}$, i.p.), administered 30 minutes before the algogen, was included as the positive control.

\section{Glutamate-induced nociception}

In an attempt to provide more direct evidence concerning the interaction of the CT with the glutamatergic system, we separately investigated whether or not the CT was able to antagonize glutamate-induced orofacial nociception in mice. The procedure used was similar to that previously described by Beirith et al., ${ }^{30}$ with some alterations. A volume of $20 \mu \mathrm{L}$ of glutamate ( $25 \mu M$ per paw prepared in phosphate-buffered saline) was injected in the right upper lip (perinasal area), using a 27-gauge needle. Animals were observed individually for 15 minutes following glutamate injection. Pain quantification was performed at this period measuring the time (in seconds) that the animals spent facerubbing the injected area with their fore- or hindpaws. Animals $(n=8$ per group) were treated with CT $(50,100$, and $200 \mathrm{mg} / \mathrm{kg}$, i.p.) or vehicle ( 1 drop of Tween 80 [0.2\%] in distilled water, the solvent for CT) 30 minutes before glutamate injection.

\section{Leukocyte migration to the peritoneal cavity}

The leukocyte migration was induced by injection of carrageenan $(500 \mu \mathrm{g}$ per cavity, i.p., $500 \mu \mathrm{L})$ into the peritoneal cavity of rats 1 hour after administration of CT (50, 100 , and $200 \mathrm{mg} / \mathrm{kg}$, i.p.), vehicle (1 drop of Tween 80 [0.2\%] in distilled water, the solvent for CT), or dexamethasone $(2 \mathrm{mg} / \mathrm{kg}$, s.c.) by modification of the technique previously described by Bastos et al. ${ }^{31}$ Mice $(n=6$ per group) were euthanized by cervical dislocation 4 hours after carrageenan injection. Shortly after, phosphate-buffered saline containing EDTA ( $1 \mathrm{~m} M$, i.p., $10 \mathrm{~mL}$ ) was injected. Immediately a brief massage was done for further fluid collection, which was centrifuged (750 $g$ for 5 minutes) at room temperature. The supernatant was disposed of, and $1 \mathrm{~mL}$ of phosphate-buffered saline was added to the precipitate. An aliquot of $10 \mu \mathrm{L}$ from this suspension was dissolved in $200 \mu \mathrm{L}$ of Turk's solution, and the total cells were counted in a Neubauer chamber, under optic microscopy. The results were expressed as the number of neutrophils $/ \mathrm{mL}$. The percentage of the leukocyte inhibition was calculated as $(1-T / C) \times 100$, where $T$ represents the treated group's leukocyte counts and $C$ represents the control group's leukocyte counts.

\section{Motor activity evaluation}

To investigate if the treatments could influence the motor activity of the animals and consequently impair the assessment of the nociceptive behavior in experimental models, the motor activity was evaluated in a Rota-rod apparatus. ${ }^{32,33}$ Initially, the mice able to remain on the Rota-rod apparatus $\left(\mathrm{AVS}^{\circledR}\right.$, São Paulo) longer than 120 seconds
(9 rpm) were selected 24 hours before the test. ${ }^{34}$ Then the selected animals were divided into five groups $(n=8$ per group) and treated intraperitoneally with vehicle (1 drop of Tween 80 [0.2\%] in distilled water, the solvent for CT), CT $(25,50$ and $100 \mathrm{~mL} / \mathrm{kg}$, i.p.), or diazepam $(3 \mathrm{mg} / \mathrm{kg})$. Thirty minutes later, each animal was tested on the Rota-rod apparatus, and the time (in seconds) it remained on the bar for up to 120 seconds was recorded after 30,60 , and 90 minutes.

\section{Total radical-trapping antioxidant parameter}

An adapted method of total radical-trapping antioxidant parameter (TRAP) assay was used to determine the capacity of CT to trap a flow of water-soluble peroxyl radical produced at constant rate, through thermal decomposition of AAPH. ${ }^{35}$ In brief, the reaction mixture containing $4 \mathrm{~mL}$ of the free radical source $(10 \mathrm{~m} M$ AAPH $)$ in $0.1 M$ glycine buffer $(\mathrm{pH} 8.6), 10 \mathrm{~mL}$ of the test samples at different concentrations, and $10 \mathrm{~mL}$ of luminol $(4 \mathrm{mM})$ as the external probe to monitor radical production was incubated at $25^{\circ} \mathrm{C}$. Trolox (a water-soluble vitamin $\mathrm{E}$ analog) was used as reference peroxyl radical scavenger molecule. The chemiluminescence produced was directly proportional to the radical generation and measured in out-of-coincidence mode (Wallac 1409 DSA liquid scintillation counter, Wallac Oy, Turku, Finland) as counts per minute. The TRAP of CT was evaluated for instantaneously inhibition of chemiluminescence as the area under curve (AUC). The total antioxidant reactivity (TAR) was calculated as the ratio of light intensity in absence of samples $\left(I^{0}\right) /$ light intensity right after CT addition $(I)$ and expressed as a percentage of inhibition. CT vehicle was $1 \%$ dimethyl sulfoxide. AUC and radical basal production were acquired by software (GraphPad Software Inc., San Diego, CA, USA) analysis of data.

\section{TBA-reactive substances assay}

TBA-reactive species (TBARS) assay was used for quantify lipid peroxidation, ${ }^{36}$ and an adapted TBARS method was used to measure the antioxidant capacity of CT using egg yolk homogenate as the lipid-rich substrate. ${ }^{35} \mathrm{In}$ brief, egg yolk was homogenized (1\% wt/vol) in $20 \mathrm{mM}$ phosphate buffer ( $\mathrm{pH} 7.4)$, and $1 \mathrm{~mL}$ of homogenate was sonicated and then homogenized with $0.1 \mathrm{~mL}$ of $\mathrm{CT}$ at different concentrations or controls in different concentrations prepared immediately before use. Lipid peroxidation was induced by addition of $0.1 \mathrm{~mL}$ of AAPH solution $(0.12 \mathrm{M})$. Trolox was used as the reference antioxidant molecule (positive control); the negative control was only CT vehicle (1\% dimethyl sulfoxide). Reactions were carried out for 30 minutes at $37^{\circ} \mathrm{C}$. After cooling, samples $(0.5 \mathrm{~mL})$ were centrifuged with $0.5 \mathrm{~mL}$ of trichloroacetic acid $(15 \%)$ at $1,200 \mathrm{~g}$ for 10 minutes. A $0.5-\mathrm{mL}$ aliquot from supernatant was mixed with $0.5 \mathrm{~mL}$ of TBA $(0.67 \%)$ and heated at $95^{\circ} \mathrm{C}$ for 30 minutes. After cooling, samples absorbance was measure using a spectrophotometer at $532 \mathrm{~nm}$. The results were expressed as percentage of TBARS formed by AAPH alone (induced control). 


\section{Scavenging activity of $\mathrm{NO}$}

NO was generated from spontaneous decomposition of $\mathrm{SNP}$ in $20 \mathrm{~m} M$ phosphate buffer ( $\mathrm{pH} 7.4)$. Once generated, NO interacts with oxygen to produce nitrite ions, which were measured by the Griess reaction. ${ }^{37}$ The reaction mixtures ( $1 \mathrm{~mL}$ each) containing $10 \mathrm{mM}$ SNP in phosphate buffer and vehicle (1\% dimethyl sulfoxide) or CT at different concentrations were incubated at $37^{\circ} \mathrm{C}$ for 1 hour. A $0.5-\mathrm{mL}$ aliquot was taken and homogenized with $0.5 \mathrm{~mL}$ of Griess reagent. The absorbance of chromophore was measured at $540 \mathrm{~nm}$. Percentage inhibition of NO generated was measured by comparing the absorbance values of negative controls (only $10 \mathrm{~m} M$ SNP and vehicle) and assay preparations. Results were expressed as percentage of nitrite formed by SNP alone.

\section{Hydroxyl scavenging activity}

The formation of $\cdot \mathrm{OH}$ (hydroxyl radical) from the Fenton reaction was quantified using 2-deoxyribose oxidative degradation. ${ }^{38}$ The principle of the assay is the quantification of the 2-deoxyribose degradation product, malondialdehyde, by its condensation with TBA. In brief, typical reactions were started by the addition of $\mathrm{Fe}^{2+}(6 \mathrm{mM}$ final concentration) to solutions containing $5 \mathrm{~m} M$ 2-deoxyribose, $100 \mathrm{mM} \mathrm{H} \mathrm{H}_{2} \mathrm{O}_{2}$, and $20 \mathrm{~m} M$ phosphate buffer ( $\mathrm{pH} \mathrm{7.2).} \mathrm{To}$ measure $\mathrm{CT}$ antioxidant activity against hydroxyl radical, different concentrations of CT and vehicle (1\% dimethyl sulfoxide) were added to the system before $\mathrm{Fe}^{2+}$ addition. Reactions were carried out for 15 minutes at room temperature and were stopped by addition of $4 \%$ (vol/vol) phosphoric acid followed by $1 \%$ (wt/vol) TBA (in $50 \mathrm{mM}$ $\mathrm{NaOH}$ ). Solutions were boiled for 15 minutes at $95^{\circ} \mathrm{C}$ and then cooled at room temperature. The absorbance was measured at $532 \mathrm{~nm}$, and results were expressed as malondialdehyde equivalents formed by $\mathrm{Fe}^{2+}$ and $\mathrm{H}_{2} \mathrm{O}_{2}$.

\section{Catalase-like activity}

The ability of CT to scavenge $\mathrm{H}_{2} \mathrm{O}_{2}$ ("catalase-like activity") was measured as described previously. ${ }^{39}$ In brief, $\mathrm{H}_{2} \mathrm{O}_{2}$ diluted in $0.02 \mathrm{M}$ phosphate buffer $(\mathrm{pH}$ 7.0) to obtain a $5 \mathrm{~m} M$ final concentration was added to microplate wells in which different concentrations was placed. The microplate was immediately placed to monitor the rate of $\mathrm{H}_{2} \mathrm{O}_{2}$ decomposition in the microplate reader set at $240 \mathrm{~nm}$. Dimethyl sulfoxide at $1 \%$ was used as the vehicle.

\section{SOD-like activity}

The ability of CT to scavenge superoxide anion ("SODlike activity") was measured as previously described. ${ }^{40}$ CT was mixed with native purified catalase $(100 \mathrm{U} / \mathrm{mL}$ stock solution) in glycine buffer $(50 \mathrm{~m} M, \mathrm{pH} 10.2)$. CT vehicle was $1 \%$ dimethyl sulfoxide. Superoxide generation was initiated by addition of $2 \mathrm{~m} M$ adrenaline, and adrenochrome formation was monitored at $480 \mathrm{~nm}$ for 5 minutes at $32^{\circ} \mathrm{C}$. Superoxide production was determined by monitoring the reaction curves of samples and measured as a percentage of the rate of adrenaline autooxidation into adrenochrome.

\section{Statistical analysis}

Data obtained were evaluated by one-way analysis of variance followed by Dunnett's test. Differences were considered to be statistically significant when $P<.05$. Data were analyzed with GraphPad Prism version 5.01 software (1992-2007, GraphPad Software Inc.).

\section{RESULTS}

The TRAP and TAR assays indicate that CT presents a significant antioxidant activity at the highest doses tested. At $100 \mu \mathrm{g} / \mathrm{mL}$ and $1 \mathrm{mg} / \mathrm{mL}$, CT inhibited the pro-oxidant pulse generated by the free radical-producing system at the TRAP assay, and TAR calculation indicates a significant antioxidant potential at $1 \mathrm{mg} / \mathrm{mL}$ (Fig. $1 \mathrm{~A}$ and B). On the other hand, all doses of CT were not able to prevent lipoperoxidation induced by AAPH in vitro in a lipid-enriched system (Fig. 1C).

To establish the profile of CT antioxidant activity, we tested the scavenger activity of CT against different reactive species. CT was able to significantly inhibit superoxide radical production at the doses of $100 \mu \mathrm{g} / \mathrm{mL}$ and $1 \mathrm{mg} / \mathrm{mL}$, as assessed by the SOD-like activity assay (Fig. 2A). However, at these same doses, CT inhibited spontaneous degradation of $\mathrm{H}_{2} \mathrm{O}_{2}$, as determined by the catalase-like activity assay (Fig. 2B). CT also demonstrated inhibition of SNP-induced nitrite production, indicating a scavenging activity of CT toward NO (Fig. 2C). On the other hand, no activity against hydroxyl radicals was observed in the 2deoxyribose degradation assay (Fig. 2D). Altogether, these results suggest that the mechanism of CT antioxidant effects observed in TRAP and TAR assays relies on its ability to scavenge $\mathrm{NO}$, superoxide, and $\mathrm{H}_{2} \mathrm{O}_{2}$ molecules, but not hydroxyl radicals.

Intraperitoneal administration of $\mathrm{CT}$ to mice produced a dose-dependent reduction in formalin-induced face-rubbing behavior (Fig. 3A). Antinociception in both the first and second phases was significantly enhanced. We tested the effect of morphine, which reduced the nociceptive behavior in both phases as well, to compare with the effect of CT and evaluate the involvement of the opioid system in the effect of CT. The effects of both CT and morphine were inhibited by naloxone, a specific antagonist of morphinomimetic receptors.

CT significantly $(P<.001)$ reduced, in a dose-dependent manner, the face-rubbing behavior induced by administration of capsaicin to mice (Fig. 3B). All doses produced an effect similar to that of morphine $(3 \mathrm{mg} / \mathrm{kg})$. Also, at doses of 100 and $200 \mathrm{mg} / \mathrm{kg}$, i.p., CT significantly decreased the facerubbing behavior induced by glutamate (Fig. 4A). In the Rota-rod test, CT-treated mice did not show any significant motor performance alterations, indicating the results shown here are not due to inhibition of motor activity (Fig. 4B).

Carrageenan $(500 \mu \mathrm{g}$ per cavity) induced leukocyte migration to the peritoneal cavity 4 hours after stimulus. Figure 5 
shows the inhibitory effect of CT on carrageenan-induced responses in higher doses $(45.9 \%$ and $65.7 \%$ at doses of 100 and $200 \mathrm{mg} / \mathrm{kg}$, respectively). The results obtained with the control group support the effect of CT because the vehicle presented no activity, and the positive control drug, dexa-
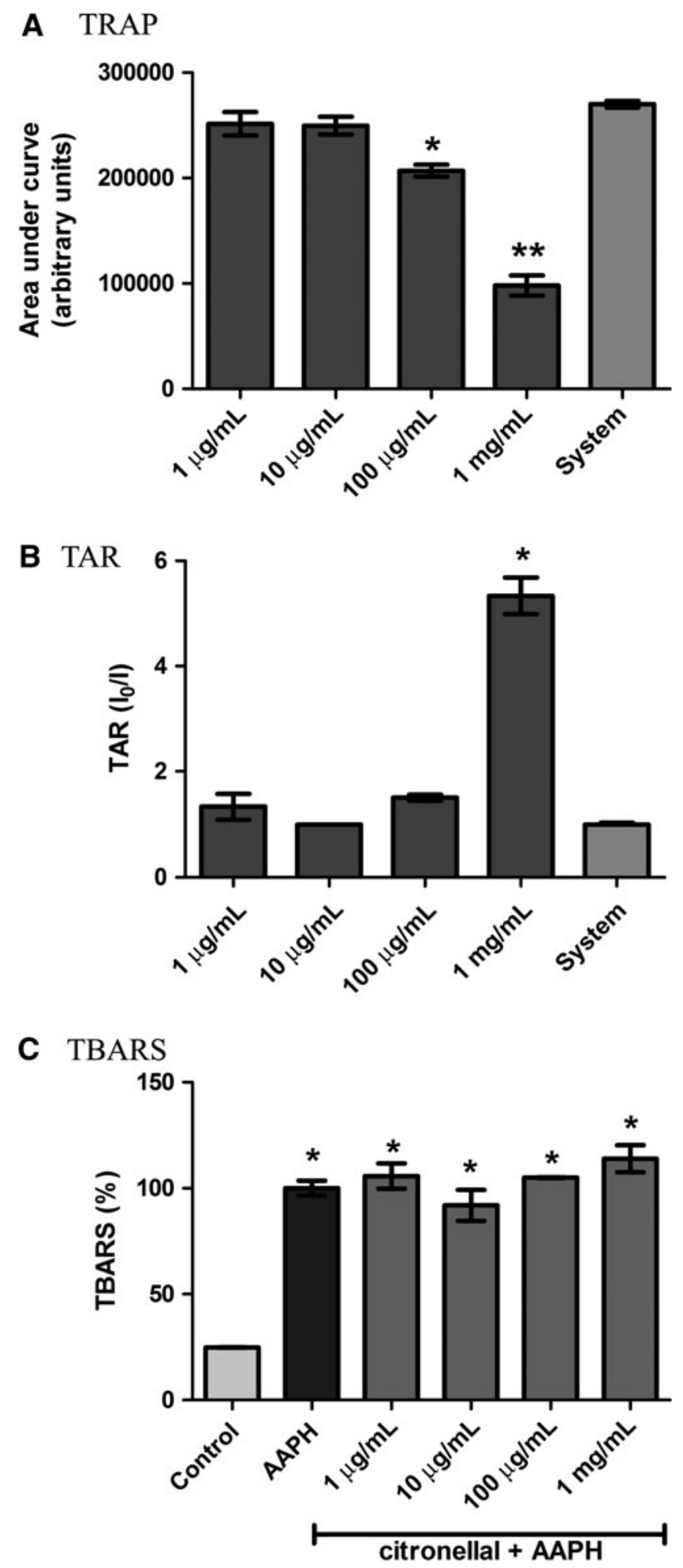

methasone $(2 \mathrm{mg} / \mathrm{kg}$, s.c.), inhibited $(92.2 \%, P<.001)$ the carrageenan-induced leukocyte migration to the peritoneal cavity.

\section{DISCUSSION}

$\mathrm{CT}$ is a monoterpenoid and the major constituent of the mixture of terpenoids that give the citronella oil its lemon scent. ${ }^{12}$ Citronella oil is widely used around the world for various purposes and is mainly obtained from plants of the genus Cymbopogon, which are collectively known as "lemongrass." ${ }^{41,42}$ Such plants are used in teas, soups, and curries in Asia and are also suitable for poultry, fish, and seafood. Lemongrass is a tall perennial grass, and the lower part of the stem is used as a component of different curry dishes in Asia. Ground pastes of lemongrass are also a common component of curry powders. ${ }^{43}$ In Thailand, lemongrass is also used to make a refreshing cold drink called "Nam Takrai," while in Brazil infusions containing lemongrass are commonly used in folk medicine as a regulator of the functions of digestive and circulatory systems. ${ }^{44} \mathrm{CT}$ and related compounds are also major constituents in $M$. officinalis ("balm," "lemon-balm," "Cidreira"), which is extensively used as tea for both medicinal and recreational purposes and as a flavoring agent in Brazil, England, and Southern Europe. Citronella oil is used in food, in soaps, as an antiseptic, and also as an insect repellent. ${ }^{14,45}$ Recently, a species of lemongrass (C. citratus) was observed to selectively induce apoptosis in malignant cancer cells, and this property was attributed to citral. ${ }^{46}$ This has led to an increase in the interest of researchers to explore the biological activities of monoterpenoids related to the Cymbopogon genus, considering these plants have been used for various medicinal and other purposes. Nonetheless, there are very few works concerning the effects of CT for internal use.

FIG. 1. Antioxidant activity and prevention of lipoperoxidation in vitro by citronellal. (A) Total radical-trapping antioxidant parameter (TRAP) of citronellal at different concentrations. Bars represent the area under the curve (arbitrary units) generated by $2,2^{\prime}$-azobis(2methylpropionamidine) dihydrochloride (AAPH), a free radical source, in the presence of different concentrations of citronellal, as described in Materials and Methods. The system is the area generated during reading of luminescence by AAPH alone. $* P<.05$, $* * P<.001$ by one-way analysis of variance with Duncan's post hoc analysis. (B) Total antioxidant reactivity (TAR) was calculated as the ratio of light intensity in the absence of samples and the light intensity right after citronellal addition and expressed as a percentage of inhibition $\left(I_{0} / I\right)$ using the same raw data. $* P<.05$ byone-way analysis of variance with Duncan's post hoc analysis. (C) Thiobarbituric acid-reactive substances (TBARS) in vitro. Lipid extracted from egg yolk was subjected to oxidative damage by incubation with AAPH, and the ability of different concentrations of citronellal to prevent TBARS formation was analyzed. Control means basal lipid peroxidation; the AAPH-alone group is considered $100 \%$ of oxidative damage. ${ }^{*} P<.05$ relative to the control group by one-way analysis of variance with Duncan's post hoc analysis. Data in all experiments represent mean $\pm S E M$ values $(n=5)$ from experiments performed in triplicate. 
A
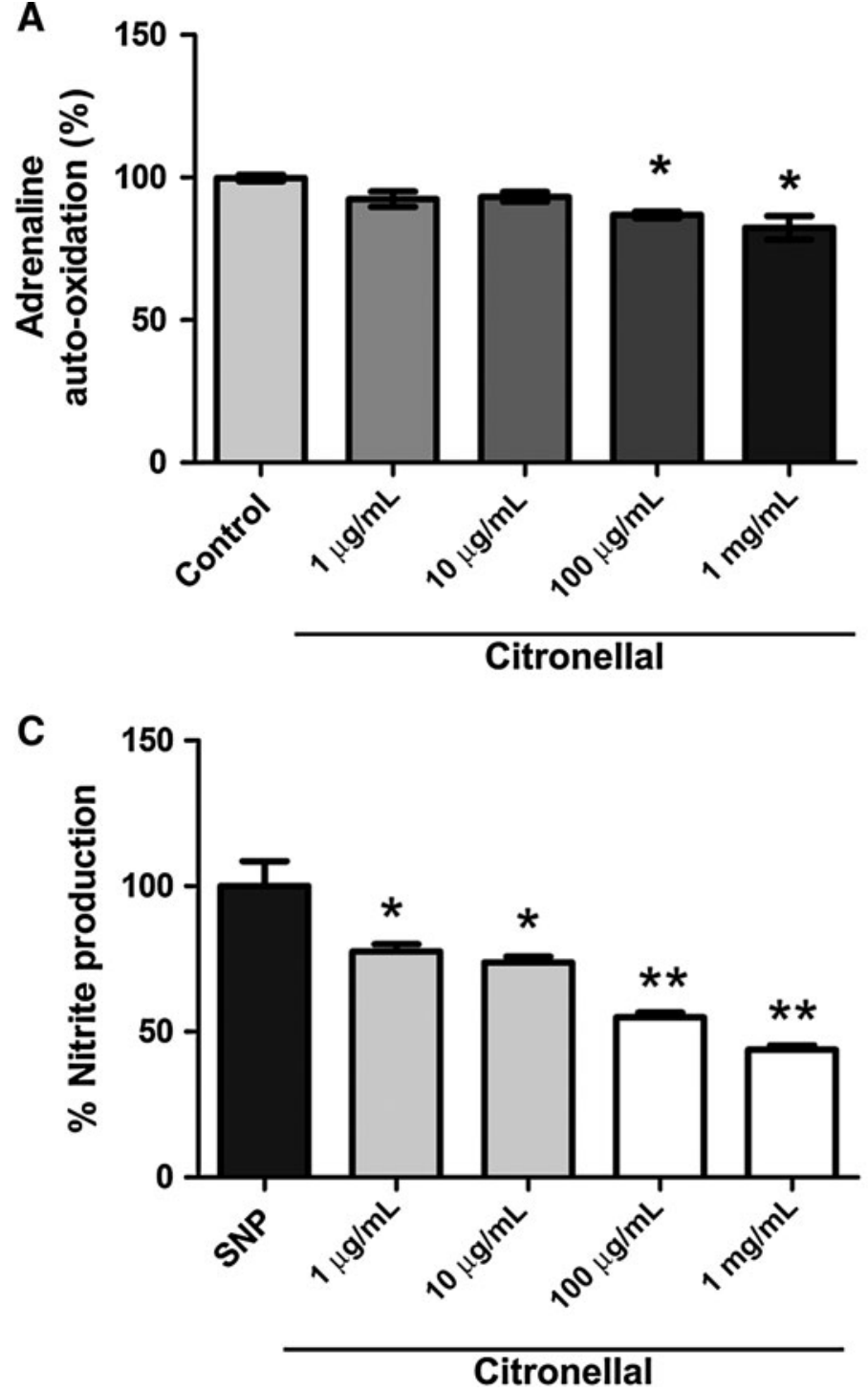
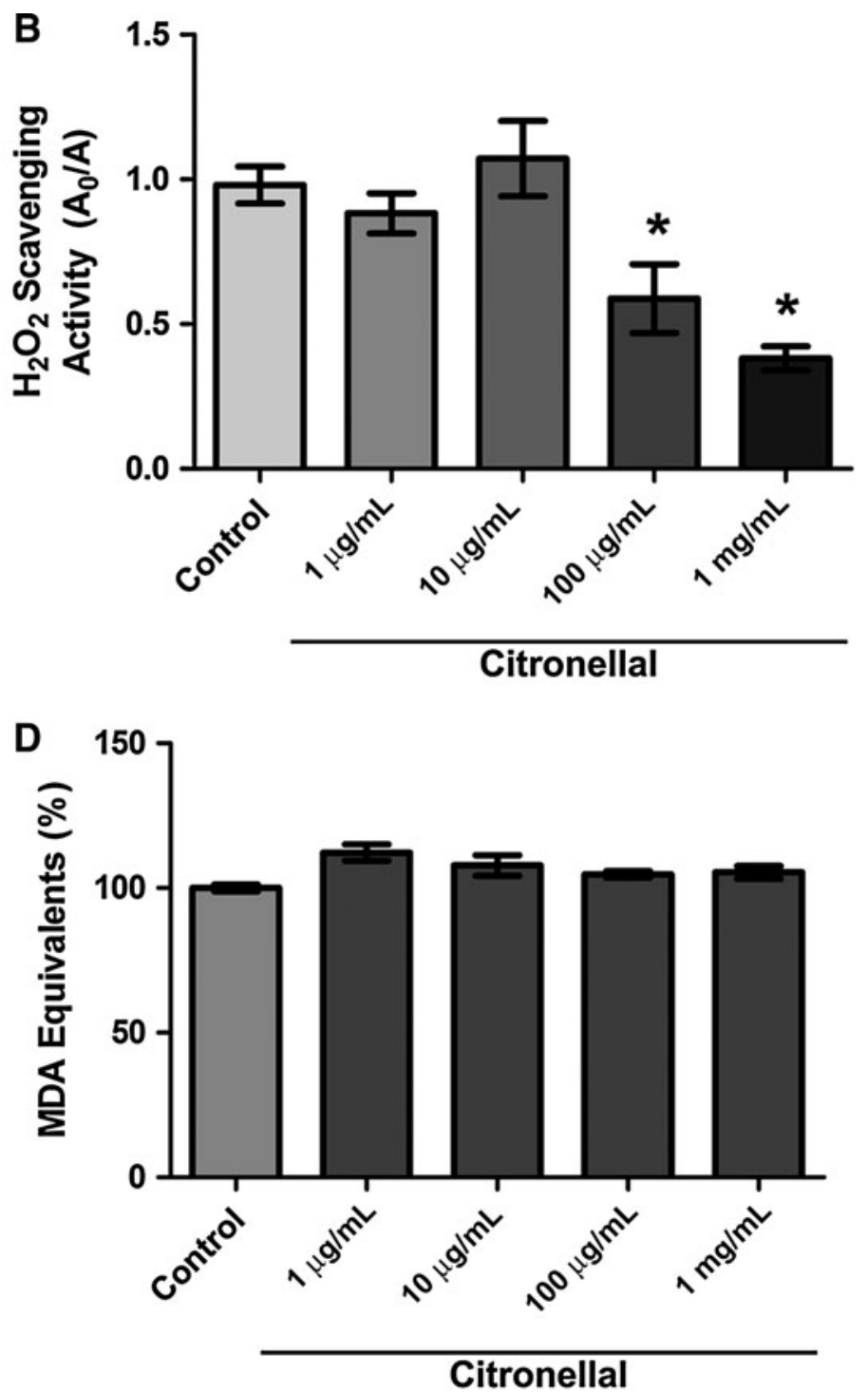

FIG. 2. In vitro characterization of citronellal antioxidant activity. (A) Superoxide dismutase-like activity. Control means spontaneous superoxide degradation. (B) Catalase-like activity. Control means spontaneous $\mathrm{H}_{2} \mathrm{O}_{2}$ degradation. (C) Nitric oxide scavenging activity. SNP means nitrite formation induced by sodium nitroprusside alone, considered as $100 \%$ of nitric oxide formation. (D) Hydroxyl radical formation. Control is 2-deeoxyribose degradation to malondialdehyde (MDA) induced by hydroxyl radicals generated by $\mathrm{H}_{2} \mathrm{O}_{2}$ and iron, considered $100 \%$ of hydroxyl radical formation in this system. Data are mean \pm SEM values $(n=5)$ from experiments performed in triplicate. $* P<.05$ in relation to control, ${ }^{*} P<.05$ in relation to *groups by one-way analysis of variance with Duncan's post hoc analysis.

It was observed that isolated CT or CT-enriched essential oils/plant extracts inhibited P-glycoprotein-mediated transport in breast cancer cells, ${ }^{47}$ exhibited anticonvulsant activity, and inhibited acetyl- and butyrylcholinesterases. ${ }^{48}$ However, there are no studies on the redox properties of CT. Considering the involvement of free radicals and related species in the molecular mechanisms underlying the pathogenesis and progression of different forms of diseases, such as cancer and neurodegenerative conditions, the study of the redox-related properties of CT may help to understand the mechanisms of its action and its efficacy to treat such conditions. Considering also the wide use of CT-containing plants and extracts in popular medicine to treat diseases related to chronic and acute forms of pain, we found interesting to evaluate its antinociceptive effect in an animal model.

Acute administration of CT on formalin-induced orofacial pain caused pronounced antinociception, suggesting a central analgesic effect. The antagonistic effect of naloxone suggests participation of the opioid system in the modulation of pain by CT. Also, the inhibitory effect observed with CT on capsaicin- and in the second phase of formalin-induced face-rubbing behavior may be a result of substance $\mathrm{P}$ release inhibition or a direct blocking action on its receptor, neurokinin-1 (NK-1), by $\mathrm{CT}^{25}{ }^{25} \mathrm{In}$ this regard, a previous study provided evidence for tonic 

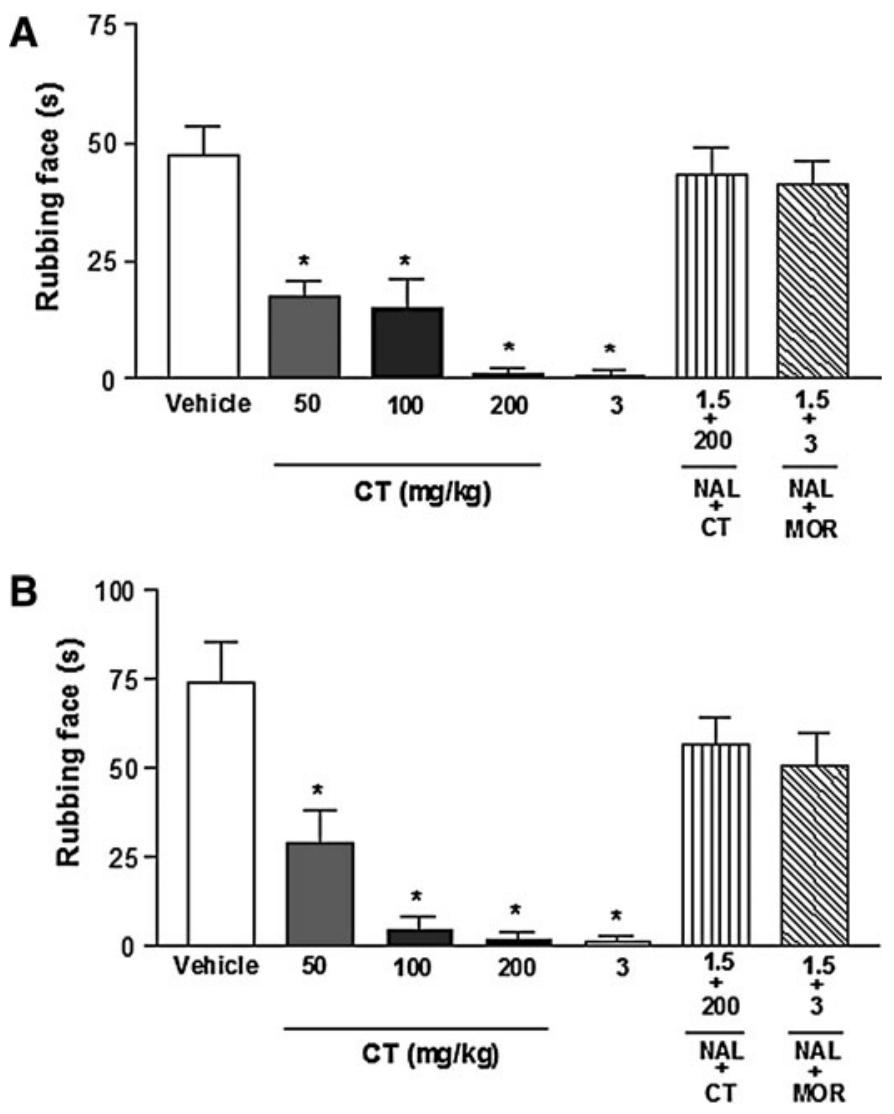

FIG. 3. Effect of citronellal (CT) on formalin-induced orofacial pain-related face-rubbing response in mice. Drugs were administered 0.5 hour before formalin injection into the right upper lip (perinasal area): (A) first phase ( $0-5$ minutes) and (B) second phase (15-40 minutes). The effects of morphine (MOR) and/or naloxone (NAL) pretreatments on the antinociceptive effects of CT $(200 \mathrm{mg} / \mathrm{kg}$, i.p.) were examined. MOR or NAL was injected 0.5 hour before formalin. Data are mean \pm SEM values from eight animals. $* P<.001$ compared with control by analysis of variance followed by Dunnett's test.

activation of NK-1 receptors, through administration of the NK-1 receptor antagonist SR14033, which blocked the second phase of the orofacial formalin test response in rats. ${ }^{49,50}$ Additionally, our results also show that CT inhibited the nociceptive response caused by right vibrissa pad injection of glutamate into mice. This nociceptive response caused by glutamate seems to involve peripheral, spinal, and supraspinal sites, and its action is mediated by $N$-methyl-D-aspartate and non- $N$-methyl-D-aspartate receptors. ${ }^{30}$ Several studies have demonstrated that those excitatory amino acid receptors are involved in nociceptive primary afferent transmission, in both the development and maintenance of painful response. ${ }^{51}$ Thus, the suppression of glutamate-induced nociception by CT treatment may be associated with its interaction with the glutamatergic system.

The results presented here indicate that $\mathrm{CT}$ exhibits a significant antioxidant activity, as seen in TRAP/TAR assays, which are widely accepted methods to reliably establish the ability of isolated molecules to act as general
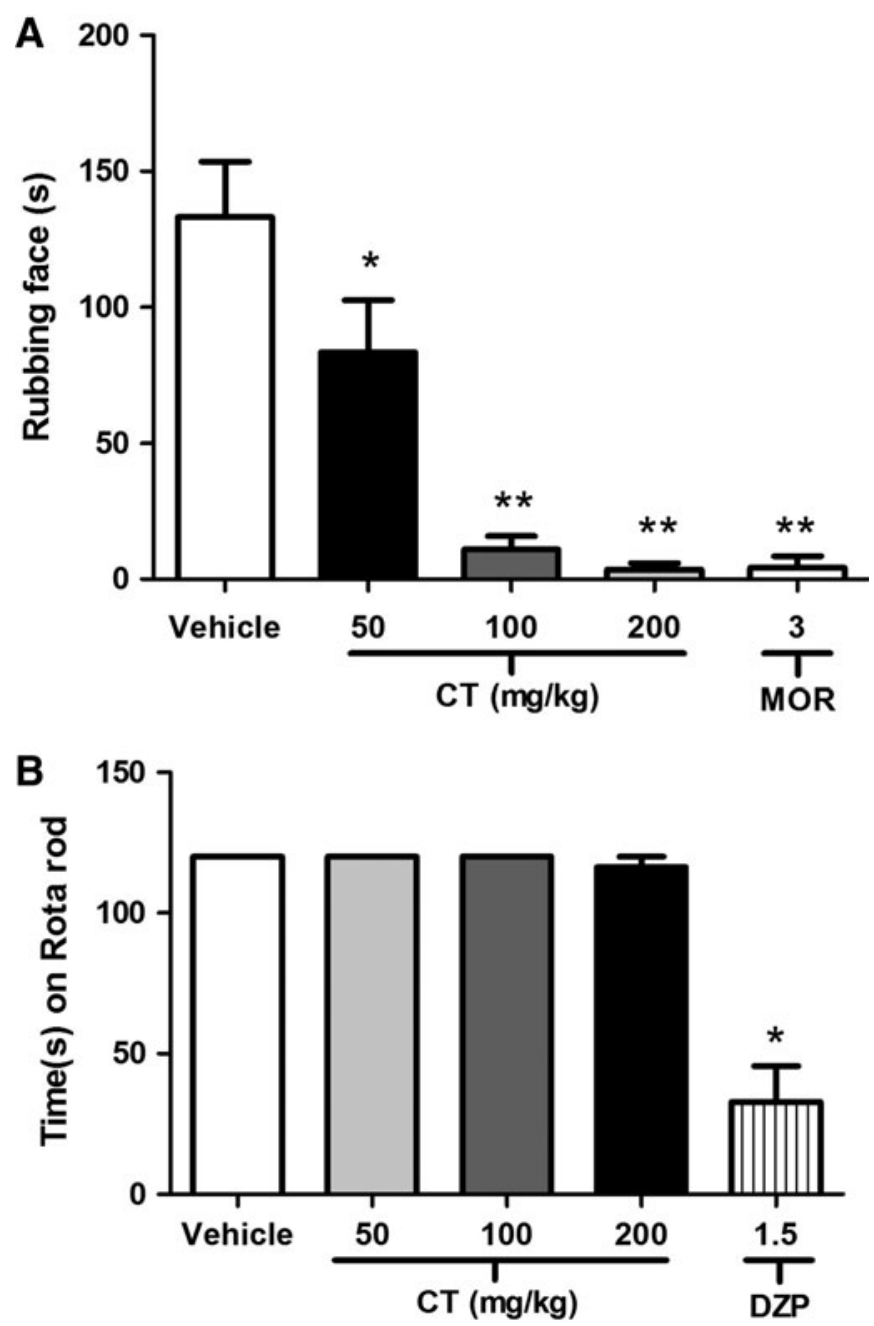

FIG. 4. Effect of CT on capsaicin-induced orofacial pain-related face-rubbing response in mice. (A) Vehicle, CT, or MOR was administered 0.5 hour before capsaicin injection into the right upper lip (perinasal area). Data are mean \pm SEM values from eight animals. $* P<.05, * * P<.001$ compared with control by analysis of variance followed by Dunnett's test. (B) Time (in seconds) on the Rota-rod observed in mice after intraperitoneal treatment with vehicle (control), CT $(50,100$, or $200 \mathrm{mg} / \mathrm{kg})$, or diazepam (DZP) $(1.5 \mathrm{mg} / \mathrm{kg})$. The motor response was recorded for the following 120 seconds after drug treatment. Data are mean \pm SEM values $(n=10)$. Statistical significance of differences versus the control group was calculated using analysis of variance followed by Dunnett's test: $* P<.001$.

antioxidants in vitro. Also, we demonstrated that $\mathrm{CT}$ is able to scavenge NO and superoxide molecules. These are relevant species to the development of oxidative and nitrosative stress, which in turn trigger diverse deleterious processes in cells. Antioxidant activities by natural products are generally thought to be responsible for the health-promoting effects observed in diets and supplementations using vegetables and other plant-derived products. Prevention of cardiac diseases, cancer, and neurodegenerative conditions observed in epidemiologic studies is ascribed to the presence of secondary metabolites in such diets and/or supplementations. Our results also have shown that CT had no 


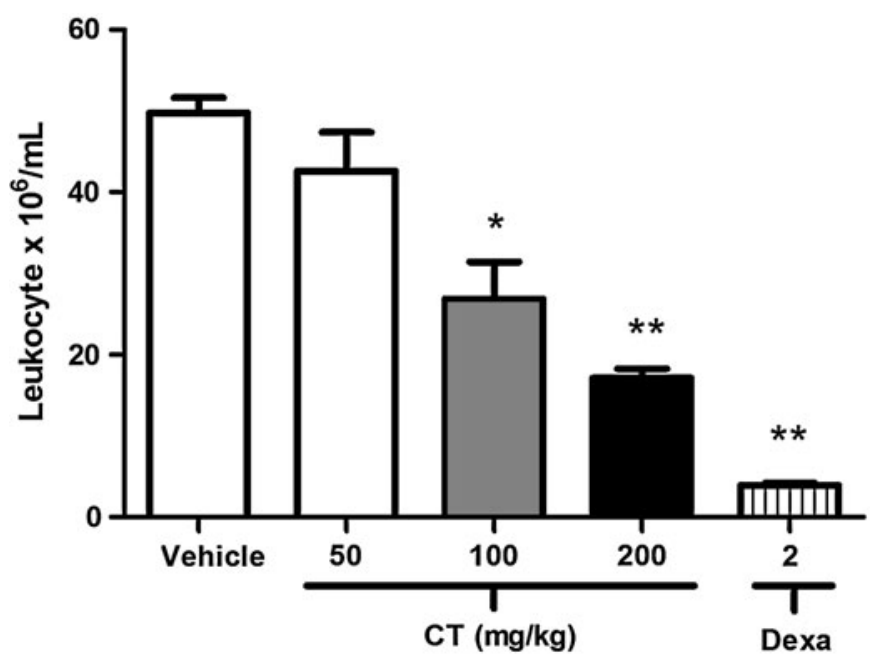

FIG. 5. Effect of CT on leukocyte migration into the peritoneal cavity induced by carrageenan in mice. Groups of mice were pretreated with vehicle (control group, $10 \mathrm{~mL} / \mathrm{kg}$, i.p.), dexamethasone (Dexa) $(2 \mathrm{mg} / \mathrm{kg}$, s.c.), or CT in concentrations of 50,100 , or $200 \mathrm{mg} / \mathrm{kg}$ (i.p.) 1 hour before carrageenan $(500 \mu \mathrm{g}$ per cavity, $500 \mu \mathrm{L}$, i.p.)-induced peritonitis. Cell counts were performed at 4 hours after the injection of carrageenan. Data are mean \pm SEM values $(n=6)$. Statistical significance of differences relative to the control group were calculated by analysis of variance followed by Dunnett's test: $* P<.01, * * P<.001$.

preventive action on free radical-induced lipid oxidation when incubated in a lipid-rich system, as seen in the TBARS assay (Fig. 1C). This result suggests that CT is not able to act directly as an antioxidant agent by directly interacting with lipids, which is the case of other lipophilic antioxidants such as $\alpha$-tocopherol. It is possible that lipid peroxidation to cell membranes in vivo may be prevented in the presence of CT, especially in stress conditions related to increased peroxyl and NO radicals. CT antioxidant action against these species may lower cellular oxidative stress levels and consequently diminish the attack of free radicals on lipid membranes, protecting these lipids against oxidation by an indirect mechanism.

We also found that CT presented a pronounced antinociceptive effect in all tests, and the results from the Rotarod test demonstrated that $\mathrm{CT}$ did not influence motor activity, which could impair the assessment of the nociceptive behavior. It is possible that such a antinociceptive effect of CT is at least in part mediated by its antioxidant actions because reactive species may play a relevant role in proinflammatory processes. ${ }^{52}$ During acute and chronic inflammations, superoxide is produced at rates that overwhelm the capacity of the endogenous SOD enzymes to remove it, resulting in superoxide-mediated injury. ${ }^{52}$ Important proinflammatory roles for superoxide include endothelial cell damage and increased microvascular permeability, ${ }^{52}$ upregulation of adhesion molecules such as intercellular adhesion molecule-1 and P-selectin that recruit neutrophils to sites of inflammation, lipid peroxidation, and oxidation, and DNA damage. Superoxide also activates redox-sensitive transcrip- tion factors including nuclear factor- $\kappa \mathrm{B}$ and activator protein-1, which in turn regulate genes encoding various pro-inflammatory and pro-nociceptive cytokines. ${ }^{52}$

$\mathrm{NO}$ is a key anti-inflammatory and cytoprotective agent when acting as a signaling molecule. We observed that CT is able to inhibit NO production by SNP in vitro, which could indicate that NO quenching by CT would enhance inflammation and nociception. However, it is important to point out that the interaction of $\mathrm{NO}$ with other reactive species results in a general loss of its "beneficial" effects; for instance, NO-mediated activation of cyclooxygenase and subsequent release of beneficial and anti-inflammatory prostaglandins is lost when superoxide production is also enhanced because interaction between superoxide and NO leads to in situ formation of peroxynitrite, ${ }^{53}$ a potent cytotoxic and pro-inflammatory reactive species. Thus, blockade of peroxynitrite formation by preventing $\mathrm{NO}$ or superoxide excessive formation and/or removal of peroxynitrite also results in cytoprotective and anti-inflammatory effects.

Cell recruitment during inflammation depends on the orchestrated release of local mediators that are responsible for local vascular and tissue changes as well as for the recruitment of host defense cells. ${ }^{54}$ The inflammation induced by carrageenan involves cell migration, plasma exudation, and production of mediators, such as nitric oxide, prostaglandin $\mathrm{E}_{2}$, interleukin- $1 \beta$, interleukin- 6 , and tumor necrosis factor- $\alpha .{ }^{55,56}$ Those mediators are able to recruit leukocytes, such as neutrophils, in several experimental models. A putative mechanism associated with this activity may be inhibition of the synthesis of many inflammatory mediators whose involvement in the cell migration is well established. However, the exposure to inflammatory mediators such as carrageenan, cytokines, and endotoxin leads to the induction of both cyclooxygenase and NO synthase (inducible NO synthase or type 2 NO synthase). ${ }^{57}$ This observation is also supported by several studies showing that the antiinflammatory activities of natural products, as monoterpenes (linalool and geranial), were a result of inhibiting NO production in carrageenan-induced inflammation on rodents. ${ }^{58,59}$ The experiments with carrageenan clearly showed that CT (100 and $200 \mathrm{mg} / \mathrm{kg}$, i.p.) inhibits leukocyte mobilization to the peritoneal cavity.

In conclusion, we showed here evidence for the first time that CT has antioxidant properties and modulates neuropathic and inflammatory pain in the test models of orofacial pain induced by formalin (through a naloxone-sensitive mechanism), capsaicin, and glutamate. The antioxidant properties of CT may be involved in the mechanism of its antinociceptive action and also possibly in other biological actions of CT. Nonetheless, future studies should address redox properties and their involvement in the mechanism of CT action in biological systems.

\section{ACKNOWLEDGMENTS}

This work was funded by CNPq, IBN-Net number 01.06.0842-00, CAPES, FAPERGS-RS, and FAPITEC-SE. 


\section{AUTHOR DISCLOSURE STATEMENT}

The authors declare they have no competing financial interests.

\section{REFERENCES}

1. Gey KF, Moser UK, Jordan P, Stahelin HB, Eichholzer M, Ludin E: Increased risk of cardiovascular disease at suboptimal plasma concentrations of essential antioxidants: an epidemiological update with special attention to carotene and vitamin C. Am J Clin Nutr 1993;57(5 Suppl):787S-797S.

2. Ramsey F, Ussery-Hall A, Garcia D, et al.: Prevalence of selected risk behaviors and chronic diseases-Behavioral Risk Factor Surveillance System (BRFSS), 39 steps communities, United States, 2005. MMWR Surveill Summ 2008;57:1-20.

3. Strine TW, Hootman JM, Chapman DP, Okoro CA, Balluz L: Health-related quality of life, health risk behaviors, and disability among adults with pain-related activity difficulty. Am J Public Health 2005;95:2042-2048.

4. Gey KF: Prospects for the prevention of free radical disease, regarding cancer and cardiovascular disease. Br Med Bull 1993; 49:679-699.

5. Gaedicke S, Zhang X, Huebbe P, et al.: Dietary vitamin E, brain redox status and expression of Alzheimer's disease-relevant genes in rats. Br J Nutr 2009;102:398-406.

6. Nishino H, Murakoshi M, Mou XY, et al.: Cancer prevention by phytochemicals. Oncology 2005;69(Suppl 1):38-40.

7. Almeida RN, Navarro DS, Barbosa-Filho JM: Plants with central analgesic activity. Phytomedicine 2001;8:310-322.

8. Quintans-Junior LJ, Souza TT, Leite BS, et al.: Phythochemical screening and anticonvulsant activity of Cymbopogon winterianus Jowitt (Poaceae) leaf essential oil in rodents. Phytomedicine 2008;15:619-624.

9. de Almeida RN, Motta SC, de Brito Faturi C, Catallani B, Leite JR: Anxiolytic-like effects of rose oil inhalation on the elevated plusmaze test in rats. Pharmacol Biochem Behav 2004;77:361-364.

10. Kortvelyessy G: Preparation of derivatives of citronellal. Acta Chim Hung Models Chem 1985;119:347-354.

11. Ernst E: Herbal remedies for anxiety - a systematic review of controlled clinical trials. Phytomedicine 2006;13:205-208.

12. Nerio LS, Olivero-Verbel J, Stashenko E: Repellent activity of essential oils: a review. Bioresour Technol 2010;101:372-378.

13. Nguefack J, Budde BB, Jakobsen M: Five essential oils from aromatic plants of Cameroon: their antibacterial activity and ability to permeabilize the cytoplasmic membrane of Listeria innocua examined by flow cytometry. Lett Appl Microbiol 2004; 39:395-400.

14. Nguefack J, Dongmo JBL, Dakole CD, et al.: Food preservative potential of essential oils and fractions from Cymbopogon citratus, Ocimum gratissimum and Thymus vulgaris against mycotoxigenic fungi. Int J Food Microbiol 2009;131:151-156.

15. Nguefack J, Leth V, Zollo PHA, Mathur SB: Use of three essential oils as seed treatments against seed-borne fungi of rice (Oryza sativa L.) under laboratory and field conditions. Phytopathology 2004;94:S75-S75.

16. Nguefack J, Leth V, Zollo PHA, Mathur SB: Evaluation of five essential oils from aromatic plants of Cameroon for controlling food spoilage and mycotoxin producing fungi. Int $J$ Food Microbiol 2004;94:329-334.
17. Hashimoto K, Yasuda T, Ohsawa K: Determination of synephrine from Chinese medicinal drugs originating from Citrus species by ion-pair high-performance liquid-chromatography. J Chromatogr 1992;623:386-389.

18. Lu YH, Zhang CW, Bucheli P, Wei DZ: Citrus flavonoids in fruit and traditional Chinese medicinal food ingredients in China. Plant Foods Hum Nutr 2006;61:57-65.

19. Parmar HS, Kar A: Medicinal values of fruit peels from Citrus sinensis, Punica granatum, and Musa paradisiaca with respect to alterations in tissue lipid peroxidation and serum concentration of glucose, insulin, and thyroid hormones. J Med Food. 2008; 11:376-381.

20. Carbajal D, Casaco A, Arruzazabala L, Gonzalez R, Tolon Z: Pharmacological study of Cymbopogon citratus leaves. J Ethnopharmacol 1989;25:103-107.

21. Carlini EA, Contar JdDP, Silva-Filho AR, da Silveira-Filho NG, Frochtengarten ML, Bueno OF: Pharmacology of lemon grass (Cymbopogon citratus Stapf). I. Effects of teas prepared from the leaves on laboratory animals. J Ethnopharmacol 1986;17:37-64.

22. Leite JR, Seabra Mde L, Maluf E, et al.: Pharmacology of lemon grass (Cymbopogon citratus Stapf). III. Assessment of eventual toxic, hypnotic and anxiolytic effects on humans. J Ethnopharmacol 1986;17:75-83.

23. Souza Formigoni ML, Lodder HM, Gianotti Filho O, Ferreira TM, Carlini EA: Pharmacology of lemon grass (Cymbopogon citratus Stapf). II. Effects of daily two month administration in male and female rats and in offspring exposed "in utero." $J$ Ethnopharmacol 1986;17:65-74.

24. Viana GS, Vale TG, Pinho RS, Matos FJ: Antinociceptive effect of the essential oil from Cymbopogon citratus in mice. J Ethnopharmacol 2000;70:323-327.

25. Holanda Pinto SA, Pinto LM, Guedes MA, et al.: Antinoceptive effect of triterpenoid alpha,beta-amyrin in rats on orofacial pain induced by formalin and capsaicin. Phytomedicine 2008;15:630 634.

26. De-Oliveira AC, Ribeiro-Pinto LF, Paumgartten JR: In vitro inhibition of CYP2B1 monooxygenase by beta-myrcene and other monoterpenoid compounds. Toxicol Lett 1997;92:39-46.

27. Luccarini P, Cadet R, Saade M, Woda A: Antinociceptive effect of morphine microinjections into the spinal trigeminal subnucleus oralis. Neuroreport 1995;6:365-368.

28. Aghabeigi B, Haque M, Wasil M, Hodges SJ, Henderson B, Harris M: The role of oxygen free radicals in idiopathic facial pain. Br J Oral Maxillofac Surg 1997;35:161-165.

29. Clavelou P, Dallel R, Orliaguet T, Woda A, Raboisson P: The orofacial formalin test in rats: effects of different formalin concentrations. Pain 1995;62:295-301.

30. Beirith A, Santos AR, Calixto JB: Mechanisms underlying the nociception and paw oedema caused by injection of glutamate into the mouse paw. Brain Res 2002;924:219-228.

31. Bastos LFS, Merlo LA, Rocha LTS, Coelho MM: Characterization of the antinociceptive and anti-inflammatory activities of doxycycline and minocycline in different experimental models. Eur J Pharmacol 2007;576:171-179.

32. Dunham NW, Miya TS: A note on a simple apparatus for detecting neurological deficit in rats and mice. J Am Pharm Assoc Am Pharm Assoc (Baltim) 1957;46:208-209.

33. Vaz ZR, Filho VC, Yunes RA, Calixto JB: Antinociceptive action of 2-(4-bromobenzoyl)-3-methyl-4,6-dimethoxy benzofuran, a novel xanthoxyline derivative on chemical and thermal models 
of nociception in mice. J Pharmacol Exp Ther 1996;278:304312.

34. Rosland JH, Tjolsen A, Maehle B, Hole K: The formalin test in mice: effect of formalin concentration. Pain 1990;42:235-242.

35. Silva EG, Behr GA, Zanotto-Filho A, et al.: Antioxidant activities and free radical scavenging potential of Bauhinia microstachya (RADDI) MACBR. (Caesalpinaceae) extracts linked to their polyphenol content. Biol Pharm Bull 2007;30:1488-1496.

36. Esterbauer H, Cheeseman KH: Determination of aldehydic lipid peroxidation products: malonaldehyde and 4-hydroxynonenal. Methods Enzymol 1990;186:407-421.

37. Granger DL, Taintor RR, Boockvar KS, Hibbs JB Jr: Measurement of nitrate and nitrite in biological samples using nitrate reductase and Griess reaction. Methods Enzymol 1996;268:142-151.

38. Lopes GK, Schulman HM, Hermes-Lima M: Polyphenol tannic acid inhibits hydroxyl radical formation from Fenton reaction by complexing ferrous ions. Biochim Biophys Acta 1999;1472:142152.

39. Aebi H: Catalase in vitro. Methods Enzymol 1984;105:121-126.

40. Misra HP, Fridovich I: The role of superoxide anion in the autoxidation of epinephrine and a simple assay for superoxide dismutase. J Biol Chem 1972;247:3170-3175.

41. Abella L, Cortella AR, Valasco-Neguerela A, Perez-Alonso MJ: Ethnobotany, volatile oils and secretion tissues of Werneria poposa from Argentina. Pharm Biol 2000;38:197-203.

42. Rivera IG, Martins MT, Sanchez PS, et al.: Genotoxicity assessment through the Ames test of medicinal-plants commonly used in Brazil. Environ Toxicol Water Qual 1994;9:87-93.

43. Simic A, Rancic A, Sokovic MD, et al.: Essential oil composition of Cymbopogon winterianus and Carum carvi and their antimicrobial activities. Pharm Biol 2008;46:437-441.

44. Figueirinha A, Cruz MT, Francisco V, Lopes MC, Batista MT: Anti-inflammatory activity of Cymbopogon citratus leaf infusion in lipopolysaccharide-stimulated dendritic cells: contribution of the polyphenols. J Med Food 201013:681-690.

45. Al-Jabr AM: Toxicity, repellency and bioactivity of seven plant oils to storage pest Rhyzopertha dominica (F.) (Coleoptera:Bostrichidae) on wheat. J Food Sci Technol Mysore 2008;45:520-523.

46. Dudai N, Weinstein Y, Krup M, Rabinski T, Ofir R: Citral is a new inducer of caspase-3 in tumor cell lines. Planta Med 2005;71:484-488.

47. Yoshida N, Koizumi M, Adachi I, Kawakami J: Inhibition of Pglycoprotein-mediated transport by terpenoids contained in her- bal medicines and natural products. Food Chem Toxicol 2006;44:2033-2039.

48. Orhan I, Kartal M, Kan Y, Sener B: Activity of essential oils and individual components against acetyl- and butyrylcholinesterase. Z Naturforsch C 2008;63:547-553.

49. Henry JL, Yashpal K, Pitcher GM, Chabot J, Coderre TJ: Evidence for tonic activation of NK-1 receptors during the second phase of the formalin test in the rat. J Neurosci 1999;19:65886598.

50. Luccarini P, Henry M, Alvarez P, Gaydier AM, Dallel R: Contribution of neurokinin 1 receptors in the cutaneous orofacial inflammatory pain. Naunyn Schmiedebergs Arch Pharmacol 2003;368:320-323.

51. Coggeshall RE, Carlton SM: Receptor localization in the mammalian dorsal horn and primary afferent neurons. Brain Res Brain Res Rev 1997;24:28-66.

52. Salvemini D, Doyle TM, Cuzzocrea S: Superoxide, peroxynitrite and oxidative/nitrative stress in inflammation. Biochem Soc Trans 2006;34:965-970.

53. Beckman JS, Beckman TW, Chen J, Marshall PA, Freeman BA: Apparent hydroxyl radical production by peroxynitrite: implications for endothelial injury from nitric oxide and superoxide. Proc Natl Acad Sci U S A 1990;87:1620-1624.

54. Luster AD, Alon R, von Andrian UH: Immune cell migration in inflammation: present and future therapeutic targets. Nat Immunol 2005;6:1182-1190.

55. Salvemini D, Wang ZQ, Wyatt PS, et al.: Nitric oxide: a key mediator in the early and late phase of carrageenan-induced rat paw inflammation. Br J Pharmacol 1996;118:829-838.

56. Loram LC, Fuller A, Fick LG, Cartmell T, Poole S, Mitchell D: Cytokine profiles during carrageenan-induced inflammatory hyperalgesia in rat muscle and hind paw. J Pain 2007;8:127-136.

57. Vane JR, Mitchell JA, Appleton I, et al.: Inducible isoforms of cyclooxygenase and nitric-oxide synthase in inflammation. Proc Nal Acad Sci U S A 1994;91:2046-2050.

58. Tan-No K, Nakajima T, Shoji T, et al.: Anti-inflammatory effect of propolis through inhibition of nitric oxide production on carrageenin-induced mouse paw edema. Biol Pharm Bull 2006;29:96-99.

59. Peana AT, Marzocco S, Popolo A, Pinto A: (-)-Linalool inhibits in vitro NO formation: probable involvement in the antinociceptive activity of this monoterpene compound. Life Sci 2006;78:719-723. 